Service social

\title{
Hommage à Francine Ouellet
}

\section{Lise Darveau-Fournier}

Volume 45, numéro 3, 1996

Santé

URI : https://id.erudit.org/iderudit/706734ar

DOI : https://doi.org/10.7202/706734ar

Aller au sommaire du numéro

Éditeur(s)

École de service social de l'Université Laval

ISSN

1708-1734 (numérique)

Découvrir la revue

Citer ce document

Darveau-Fournier, L. (1996). Hommage à Francine Ouellet. Service social, 45(3),

7-8. https://doi.org/10.7202/706734ar d'utilisation que vous pouvez consulter en ligne.

https://apropos.erudit.org/fr/usagers/politique-dutilisation/ 


\section{Hommage à Francine Ouellet}

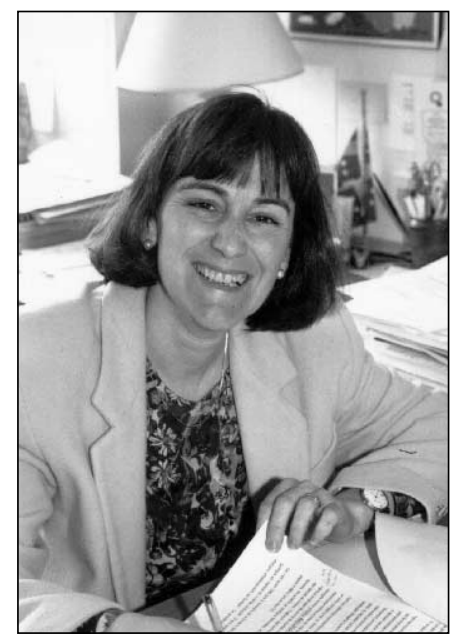

L'École de service social et la Faculté des sciences sociales de l'Université Laval sont dans la tristesse à la suite du décès d'une de leurs professeures, Francine Ouellet, survenu le 2 janvier dernier, à la suite d'un combat ardu contre le cancer. Je veux rappeler son souvenir en mettant particulièrement en évidence ses qualités personnelles et professionnelles, qui ont coloré ses enseignements, ses travaux de recherche, ses publications, ses activités de participation interne et externe.

Professeure depuis 1976, Francine Ouellet a eu une carrière remplie de succès dans toutes les sphères de la vie universitaire. Elle nous lègue en héritage de nombreuses réalisations tant en enseignement qu'en recherche et en diffusion des connaissances. Elle est demeurée active jusque dans ses dernières semaines de vie, démontrant une détermination remarquable dans l'accompagnement des étudiants et étudiantes qu'elle dirigeait, dans la passation de ses responsabilités administratives et de recherche, ainsi que dans la dernière révision d'un de ses livres en vue de sa réédition.

Francine Ouellet était reconnue comme une professeure compétente et rigoureuse, soucieuse non seulement de la qualité de son enseignement et de la réussite de ses étudiantes et étudiants, mais aussi de leur bien-être. 
Les nombreux témoignages reçus lors de son décès la qualifient tous de très disponible, accueillante, à la fois douce et volontaire, attentionnée envers ses collègues comme envers les étudiantes et les étudiants.

Elle s'engageait à fond dans tout ce qu'elle entreprenait. Chercheure reconnue par différents organismes subventionnaires et appréciée par ses pairs, elle était - depuis cinq ans codirectrice puis directrice du CRI-VIFF (Centre de recherche interdisciplinaire sur la violence familiale et la violence faite aux femmes). Francine attachait une grande importance à la diffusion des résultats de ses recherches aux intervenants sociaux du réseau de la santé et des services sociaux comme à ceux des groupes communautaires, et à leur utilisation dans la perspective d'améliorer les services aux personnes concernées, particulièrement les femmes et les familles aux prises avec des problèmes de violence.

Je résumerai la personnalité de Francine Ouellet en la qualifiant de professeure dévouée, de chercheure engagée et de collègue attentionnée. Elle était aussi une femme d'équipe, une animatrice hors pair, une véritable rassembleuse, le tout enrobé de créativité, de dynamisme et d'humour. Au-delà de sa vie professionnelle, Francine Ouellet était une femme attachante, qui respirait la joie de vivre, dont les rôles d'épouse et de mère demeuraient en tête de liste de ses priorités.

Francine Ouellet demeurera une professeure modèle et une source d'inspiration pour ses collègues et les étudiantes et étudiants de l'École de service social. Nous lui en sommes profondément reconnaissants. 